Gell, P. G. H., Harington, C. R., and Pitt-Rivers, R. (1946): Brit. J. exp. Path., 27, 267.

Heremans, J. F., and Vaerman, J. P. (1962): Nature (Lond.), 193, 1091.

LANDSTEINER, K., The Specificity of Serological Reactions, Harvard Univ. Press, Cambridge, Mass., Rev. Edit., 1945.

LEVINE, B. B. (1960a): J. exp. Med., 112, 113.

LEVINE, B. B. (1960b): Nature (Lond.), 187, 939.

LEVINE, B. B. (1960c): Nature (Lond.), 187, 940.

LeVINE, B. B., and OVARY, Z. (1961): J. exp. Med., 114, 875.

LeVINE, B. B. (1961a): Arch. Biochem. Biophys., 93, 50

Levine, B. B. (1962): J. Med. Pharm. Chem., 5, 1025.

Levine, B. B. (1963): J. exp. Med., 117, 161 .

LEVINE, B. B., and Price, V. H. (1964): Immunology, 7,542 .

LEVINE, B. B. (1964a): Immunology, 7,527.

LEVINe, B. B. (1964b): Nature (Lond.), 202, 1008.

LeY, A., Harris, M., BRINKLeY, B., Liles, J., and CaHaN, A. (1958): Science, 127, 1118.

NussenzWeig, R. S., Merryman, C., and Benacerraf, B. (1964): J. exp. Med., in Press.
OVARY, Z., Benacerraf, B., and Bloch, K. J. (1963) J. exp. Med., 117, 951 .

PARKER, C. W., ShAPIRO, J., KeRN, M., and EISEN H. N. (1962): J. exp. Med., 115, 821 .

Parker, C. W., and ThIEL, J. A. (1963): J. lab. Clin Med. (Abstr.), 62, 988.

Rytel, M. W., Klion, F. M., Arlander, T. R., ande Miller, L. F. (1963): J. Amer. med. Ass., 186, 894.

SCHWARTZ, R. H., and VAughan, J. H. (1963): J. Amer. med. Ass., 186, 1151.

Siegel, B. B. (1962): in Allergology, Pergamon Press, ஸึ New York, 1962 , p. 125 .

Siegel, B. B., and Levine, B. B. (1964): J. Allergy; in Press.

Thiel, J. A., and Parker, C. W. (1963): Presentedo at 19th Annual Meeting, American Academy of Allergy, March 12, 1963.

Van Arsdal, P. P., O'Rourke, T. K., Horan, J. D., and KaMASAKA, Y. (1963): J. Amer. med Ass., 186, 118 .

WATSON, K. C., Joubert, S. M., and BenNetT M. A. E. (1961): Immunology, 4, 193

\title{
CUTANEOUS REACTIONS TO PENICILLIN
}

\author{
C. D. Calnan
}

Professor of Dermatology, University of London, The Institute of Dermatology, St. Johns Hospital for Diseases of the Skin, Leicester Square, London, W.C.2.

THE purely cutaneous reactions to penicillin are nowadays infrequent and relatively unimportant. They consist of varying degrees of acute or chronic non-specific inflammation, with or without abscess formation. They were more commonly encountered with less pure penicillins and depôt preparations sometimes injected intradermally or subcutaneously rather than intramuscularly.

All other reactions with manifestations in the skin are part of a general hypersensitivity state, although they may not necessarily be mediated by a specific antibody directed against the drug. In this regard penicillin is similar to sulphonamides in the very diverse types of adverse reaction which it is capable of producing. The factors determining the type of hypersensitivity reaction in an individual patient are mostly obscure, with the possible exception of contact dermatitis. In the latter case, the route of administration-application to the cutaneous or a muco-orificial surface-is of paramount importance.

In the United States, there are well over a hundred preparations of penicillin available to be fed, injected, spread, insufflated and sprayed $\bar{\varnothing}$ into every conceivable cavity and surface of the body (Welch, Lewis, Weinstein and Boeckman, 1957). Individuals who have neverreceived penicillin are a fast diminishing group, a result of mass production and the availability of this cheapest of all antibiotics.

\section{Incidence}

If one accepts any undesired or unexpected sequela as a reaction to the drug, the incidence of penicillin reactions can be very high, being윽 dependent partly on the criteria of the physi- $\rightarrow$ cian. Moore's (1946) figure is $0.56 \%$, while Cormia, Jacobsen and Smith (1946) registered it as high as $60 \%$. The variation is, of course, partly due to uncritical acceptance of any symptoms and signs, and partly due to the absence of satisfactory methods of proof. Well controlled drug trials have shown thato

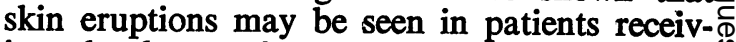
ing placebos as frequently as an active agent. Saline injections can induce the rash, arthralgia, 
pruritus and fever of "serum sickness". In an English venereal disease clinic 7,300 injections of four repository penicillins were given to 895 patients over 11 years (Willcox and Fryer, 1957). The reported incidence of probable drug reactions was $2.9 \%$, and of possible reactions $4.8 \%$. This experience is representative of those of most physicians.

All too rarely are the reported reactions related to the numbers of persons at risk, or the quantities used. The Food and Drug Administration of the United States surveyed the reactions to antibiotics in 800 hospitals over a four year period (Welch et al., 1957). Of those attributable to penicillin there were 793 cases of anaphylactoid shock, with 72 deaths (a mortality of 9\%). The preparations used in these cases are shown in Table I.

TABLE I

Penicillin Preparations used in Instances of Anaphylactoid Shock

(From Welch, Lewis, Weinstein and Boeckman, 1957)

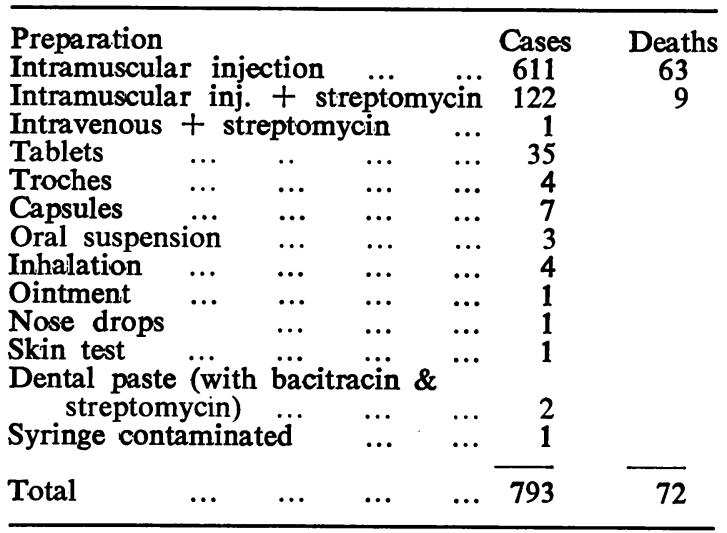

It is chastening to note the cases from noninjected preparations, and in some the amount of the drug absorbed must have been very small indeed.

During the same period there were 1,616 reactions classified as "not severe" (Table II) but clearly there must have been a very much larger number of minor reactions which presumably did not merit attention. Urticaria and/or angio-neurotic œdema account for the vast majority.

A group of 36 general practitioners in Australia (Hsu and Evans, 1959) surveyed 6,832 of their patients who had received penicillin over a ten month period. A total of $88(1.3 \%)$ developed reactions. The incidence varied considerably with the preparations used.
TABLE II

Manifestations of Moderately Severe Penicillin Reactions (From Welch et al., 1957)

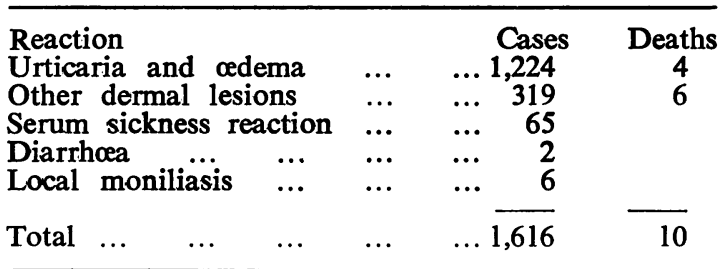

\section{Predisposing Factors}

There are no marked age or sex differences, although the Australian survey reported a male/female ratio of 2 to 1 . In the F.D.A. survey the youngest patient with anaphylaxis was two weeks and the eldest 89 years. The highest incidence is in the 20 to 50 age group.

Genetic factors have not been stressed but familial instances are not uncommon. Recently I saw a man who developed œdema of the face after an injection of the drug. Two (nonidentical twins) of his three children had had swelling of the tongue and lips after receiving oral penicillin.

Repeated dosage undoubtedly increases the risks. The more often a patient receives penicillin, the greater his chances of developing an adverse reaction.

Opinions vary on the relevance of a personal or family history of asthma, hay fever or atopic eczema. But there is a strong feeling that atopic individuals are more susceptible to anaphylactoid reactions. In the New York survey (Rosenthal, 1962) of fatal cases, no enquiry was made in 14, three suffered from asthma, seven had a positive history, while in three the relatives stated that the patient had an atopic history. In only one was there a negative history.

The route of administration is of great importance. Injection direct into a vein or the cerebrospinal cavities carries a considerable risk. The vast majority of severe reactions follow intramuscular injection (Table I), but it is probably the most frequently used route. In descending order of risk are the subcutaneous, intradermal, oral and topical routes.

Certain preparations of the drug appear to be more hazardous. This was one of the objectives of the study by the Australian group of practitioners. They found that benzathine penicillin produced an incidence of $3.8 \%$ reactions, and procaine penicillin $1.4 \%$, compared with $0.5 \%$ with oral preparations. This conclusion is in agreement with another study 
in which six out of 32 patients $(15.6 \%)$ on monthly benzathine penicillin developed reactions (Hsu and Evans, 1958).

\section{Morphology}

The patterns and microscopic appearances of eruptions following penicillin therapy are quite non-specific (Table III). Each of them may be produced by other agents or appear without identifiable cause.

TABLE III

Cutaneous Lesions Associated with Penicillin Therapy
Erythemas

Urticaria and œdema

Purpura

Bullæ

Exfoliative dermatitis

Fixed erythema

-Ide reaction
Erythema nodosum

Erythema multiforme

Stevens-Johnson

Henoch-Schönlein

syndrome syndrome

Lupus erythematosus

Periarteritis nodosa
The erythematous and urticarial reactions are far and away the most frequent. In the mildest forms they may be confined to the local area of administration, such as round an injection site, and may not spread further. Sometimes it will be manifest as oedema only, and in the case of lozenges may cause localised swelling of the tongue, and the oral, pharyngeal or laryngeal mucosa, and the face. The erythema may be blotchy and macular, maculo-papular or scarlatiniform. A special variety is the fixed patch or patches which become swollen or bullous and pigmented in each attack (Canizares, 1951; Sobel, 1951; Calnan and Verma, 1961). Urticaria may be part of the serum sickness syndrome which is manifest by fever, itching, œdema, painful swollen joints, lymphadenopathy and eosinophilia. The incubation period is from five to 21 days, and it may last for days, weeks or months. Occasionally the urticarial element persists for months or years as a chronic urticaria.

Purpura may be an accompaniment of the erythematous lesions or occur alone. It is of the anaphylactoid type and unaccompanied by thrombocytopenia. Occasionally, a widespread bullous eruption is encountered and a number of instances of exfoliative dermatitis have been reported, with some fatalities. Allergic reactions to penicillin appear more frequently in patients with an active dermatophyte infection and trichophytin sensitivity. In such instances the drug may induce the appearance of a characteristic trichophytide-like or -ide reaction which may be vesicular and localised toำ the hands and feet, or more widespread ands generalised when it is erythematous, papular or. follicular.

The clinical syndromes of erythema nodo $\stackrel{\overrightarrow{5}}{\rightarrow}$ sum, erythema multiforme and the Stevens은 Johnson syndrome, Henoch-Schönlein purpura 흔 and periarteritis nodosa which follow penicillin therapy, have no special features. Systemic lupus erythematosus has been attributed to, ores claimed to be aggravated by penicillin (Gold, $\overrightarrow{0}$ 1951); but as with other suspected drugs thereis disagreement as to whether the mere pre- $\vec{\omega}$ sence of the L.E. cell phenomenon necessarilyo indicates the systemic disease.

\section{Diagnosis}

The requirements for accurate diagnosis should be (1) a history of exposure to peni- cillin, (2) an eruption of an acceptable morph $\dot{0}-\vec{N}$ logical pattern, and (3) proof of specific hyper- -0 sensitivity to the drug. Only rarely are these ${ }_{-}$ criteria satisfied. Many patients are unaware $\square$ that they have received penicillin. The label- $\odot$ ling of all drugs by pharmacists and doctors $\frac{\Phi}{3}$ should help, as well as the habit of actualty telling the patient. But many sources of pengcillin are occult-milk foods, vaccines, dental $\vec{\emptyset}$ treatments, compound preparations and cos + taminated syringes. The allergenicity of pentcillin is not destroyed by boiling.

The greatest barrier to accurate diagnosis, however, is the absence of a reliable in vitro or in vivo test procedure. It is widely agreed $\stackrel{\square}{\square}$ that the results of in vivo tests are quite $\stackrel{2}{\Rightarrow}$ unreliable, being positive in far less than half $\frac{3}{3}$ the known reactors. An intradermal test in a $=$ patient while actually manifesting serumo sickness or soon afterwards may be negative. The possible explanations for this phenomenon are discussed elsewhere (Calnan and Verma, $\dot{0}$ 1961). However, there seems little doubt that the sensitivity wanes with time, sometimes $\delta$ rapidly.

At present, it must be admitted that the 을 diagnosis of a penicillin reaction rests largely $D$ on circumstantial evidence. Over the head of every physician hangs a sword of Damoclesthe fear of anaphylactic shock. As a result of it, I feel sure that penicillin reactions are $N$ overdiagnosed and many patients' notes are $\mathrm{N}$ wrongly labelled "Allergic to Penicillin." o Such precautions undoubtedly provide for $\varphi$ safety, but not for accuracy. Some of these patients have been re-injected without unto-? ward affect. 
In 1956 Feỉnberg and Feinberg made an oft-quoted editorial statement. With reference to the serum sickness syndrome they wrote, "A person who has had this type of reaction is more likely to experience a similar reaction a second time, but, nevertheless, a large percentage of such people can take a second injection with impunity." Alas, no evidence is provided in support of the statement. Many instances are reported of patients showing a second reaction to penicillin, but few of reactors receiving a second injection without ill effects.

Most significant, however, is Myhre's (1956) report of a patient who received one mega unit daily for three days without trouble, after experiencing a severe anaphylactoid shock from penicillin two months earlier.

\section{Test Procedures}

Every effort should be made to prove penicillin sensitivity by test procedures. A small proportion of reactions are due to other constituents of the preparations used. For example, in contact dermatitis the base, preservatives, or other additives should be included in patch testing at the same time. Procaine sensitivity accounts for a number of reactions to depôt penicillins and should always be tested separately.

The details of the investigational methods have been described by Dr. Parker, and the penicilloyl polylysine antigen test by Dr. Levine. Whatever method is used with standard penicillin solutions, it must be admitted that the majority of patients give negative results when tested within a few weeks or months of a clinical reaction. Even the most extreme examples of sensitivity diminish with time. Borrie's $(1961,1963)$ patient gave a positive reaction to 1 unit of penicillin, but two years later was far less sensitive.

Bettley, Price and Shrank (1962) and I (Calnan and Verma, 1961) have independently failed to confirm the claimed advantages of a test antigen made by incubating penicillin $G$ with gamma globulin (Rajka and Vincze, 1958).

The greatest success had been achieved by Shelley (1963) using his in vitro basophil degranulation test. In his hands it appears to be entirely reliable, but it is disappointing that even after two years, it has not proved technically satisfactory in most other laboratories though confirmed by Katz, Gill, Baxter and Moschella (1964) with his help. Their false negative figure is $35 \%$. One hopes that other workers will persist in their efforts, and that it will become a practical routine procedure.

The test for hæmagglutinating antibodies is also not yet entirely reliable; positive reactions vary from $50-100 \%$ with an average of $67 \%$ (Van Arsdel, O'Rourke, Horan and Kumasaka, 1963), and there is the added problem of false positives.

\section{TABLE IV}

Conditions for which Penicillin was Administered in 30 Fatal cases of Anaphylaxis

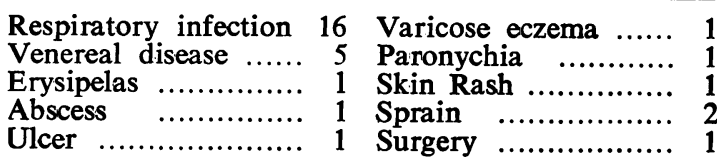

\section{Prophylaxis}

Attention to a number of common sense precautions will help to keep the incidence of reactions to a minimum, and diminish their severity.

1. All patients should be asked if they have received penicillin previously, and whether or not they showed any adverse reaction to it.

2. Penicillin should only be prescribed for sound therapeutic indications, which the physician should feel able to defend in the case of a reaction. In a series of 763 patients studied in New England, only half the prescriptions were considered justifiable; while it has even been suggested that no more than $5 \%$ of all the prescriptions in the United States can be justified. Especially revealing is the list of clinical conditions for which the drug was given in 30 cases of fatal anaphylaxis in New York City (Table IV).

3. The dosage used should be the minimal commensurate with the therapeutic needs. There is no merit in the sledge-hammer approach of overdosage.

4. The route of administration used should be the safest one, having regard to therapeutic requirements. The order of preferences is oral, subcutaneous, intramuscular, intravenous.

5. The preparation used should be the safest compatible with the patient's needs. More reactions occur with benzathine penicillin and depôt types. 
6. Be prepared for reactions. Emergency facilities should always be immediately available, although in many fatal cases death is so instantaneous that they could not have saved life. The emergency pack consists of a tourniquet, an intravenous infusion set, five per cent dextrose saline, epinephrine, diphenylhydramine $\mathrm{HCl}$, airways and oxygen, hydrocortisone for intravenous use, and penicillinase (Neutrapen).

Can one administer any prophylactic at the time of giving the drug? Antihistamines mixed with penicillin are valueless. Corticosteriods could be of value and should be used in the very rare instances when a patient is suspected of being penicillin sensitive and requires the drug in preference to other available antibiotics.

\section{Treatment}

If a patient with shock does not die instantaneously, the treatment is:

For urticaria or the serum sickness syndrome epinephrine $(0.5$ to $1.0 \mathrm{ml}$. of a 1 in 1,000 solution) should be given first, and repeated if necessary; it can be followed by intravenous aminophylline $(250 \mathrm{mg}$. in $10 \mathrm{ml}$.). For more severe cases, system corticosteroids are the most valuable, while for cases of average severity, full dosage of anti-histamines are indicated. Both drugs should be continued for about two weeks after the reaction has subsided. Penicillinase (1 million units in $2 \mathrm{ml}$.) should only be used for severe cases.

Apart from these measures the treatment is symptomatic. The patient and his family doctor must be informed of his hypersensitivity and of the risks of future penicillin administration. His medical records must be marked in an appropriate way.

Desensitization to penicillin is possible for both immediate type allergy, and contact dermatitis, but is now rarely used because of the availability of alternative antibiotic and chemotherapeutic agents.

\section{Summary}

Hypersensitive reactions to topically applied penicillin are manifest as contact dermatitis. A positive patch test is obtained without difficulty and the antigenic determinant is in the penicillin nucleus.
Cutaneous reactions to systemic penicilli are very diverse. The incidence is usuall 8 below 5\%. Diagnostic test procedures are inadequate. Hence, diagnosis is based on: circumstantial evidence and the morphology of the skin eruptions. None of the latter are diagnostic but include erythemas, urticario? purpura, bullous lesions, exfoliative dermatitis erythema nodosum, erythema multiforme and some disease syndromes such as lupus eryther matosus and periarteritis nodosa.

Patients who receive repeated doses, are in the age group 20 to 50 , and those who have a history of atopy, are more susceptible.

All forms of skin tests are frequently nega tive. The "hypersensitivity" may not bo permanent. The mechanisms of reaction may not all be antibody based.

Treatment is mainly symptomatic. Pen? cillinase may be helpful. Desensitization is possible. Prophylaxis with antihistamines is not effective.

\section{REFERENCES}

Bettley, F. R., Price, E. C. V., and Shrank, A. (1962): Acta allerg. (Kbh.), 17, 442.

Calnan, C. D., and Verma, B. S. (1961): Trans DSt John's Hosp. derm. Soc. (Lond.), 47, 146.

Canizares, O. (1951): Arch. Derm. Syph. (Berl.), 800.

Cormia, F. W., Jacobsen, L. C., and SMith, E. IS (1945): Bull. U.S. Army med. Dept., 4, 694.

De WeCK, A. L., and EISEN, H. N. (1960): J. exp Med., 112, 1227.

FeINBERG, S. M., and FeinBerg, A. R. (1956): Amer. med. Ass., 160, 778.

Gold, S. C. (1951): Lancet, i, 268.

GuTHE, T., IDSOE, O., and WillCox, R. R. (1958) Bull. Wld. Hlth. Org., 19, 3.

Hsu, I., and Evans, J. M. (1959): Med. J. Aust., 827.

Hsu, I., and Evans, J. M. (1958): New Engl. J. Med 259,581 .

KATZ, H. I., GILl, K. A., BaXter, D. L., and Moschella, S. L. (1964): J. Amer. med. Ass? 188, 351.

MOORE, J. E. (1946): Penicillin in Syphilis. Charleş C. Thomas. Springfield, Illinois.

RAJKA, G. Jr., and VinCZE, E. (1958): Ann Allergy 16, 291.

Rosenthal, A. (1958): J. Amer. med. Ass., 167, 1118 . SHELley, W. B. (1963): J. Amer. med. Ass., 184, 1710

SOBEL, N. (1951): Arch. Derm. Syph. (Berl.), 63, 801 .

Van Ardsel, P. P., O'Rourke, T. K., Horan, J. D只 and Kumasaka, Y. (1963): J. Amer. med. Ass. 185, 584.

Welch, H., LeWis, C. N., Weinstein, H. I., anळ BoecKMan, B. B. (1957): Antibiot. Med. Brit. Ed.Фั iv, 800 .

Willcox, R. R., and FRYERS, G. R. (1957): Brit. $\overrightarrow{J_{\bar{T}}}$ Vener. Dis., 33, 209. 